\title{
Neuropsychological performance in patients with subcortical stroke
}

\author{
Perfil neuropsicológico em pacientes com lesões vasculares subcorticais \\ Silviane Pinheiro Campos de Andrade', Sônia Maria Dozzi Brucki², Orlando Francisco Amodeo Bueno², \\ José Ibiapina Siqueira Neto ${ }^{4}$
}

\begin{abstract}
Vascular cognitive impairment ( $\mathrm{VCl}$ ) is characterized by cognitive compromise predominantly of executive dysfunction. Objectives: To assess cognitive functions in $\mathrm{VCl}$, focusing on executive functions, to observe functional losses in relation to activities of daily living (ADLs) and to detect early symptoms prior to the onset of dementia. Methods: We evaluated healthy subjects matched for gender, education and age to patients with diagnosis of subcortical vascular disease who had a stroke classified into three groups: 1) vascular lesions and no impairment; 2) vascular cognitive impairment with no dementia (VCIND); 3) vascular dementia (VaD). Results and discussion: The performance on neuropsychological tests differed among groups, worsening with increased impairment level. The probable VaD group demonstrated impaired performance in memory, processing speed and verbal production, while the VCIND group showed attention deficits. Conclusion: Impairment in executive functions and difficulties in ADLs allow us to differentiate levels of impairment in groups of subcortical vascular disease.
\end{abstract}

Key words: cognitive impairment, vascular dementia, neuropsychological assessment, activities of daily living.

\section{RESUMO}

O comprometimento cognitivo vascular (CCV) é caracterizado por comprometimento cognitivo predominantemente sob a forma de disfunção executiva. Objetivos: Avaliar as funções cognitivas no CCV, enfocando as funções executivas, observar as perdas funcionais em relação às atividades cotidianas (AVDs) e detectar os primeiros sintomas antes do início da demência. Métodos: Foram avaliados indivíduos controles saudáveis pareados por sexo, escolaridade e idade com pacientes com diagnóstico de doença vascular subcortical que sofreram derrame classificados em três grupos: 1) lesões vasculares sem déficit; 2) comprometimento cognitivo vascular sem demência (CCVSD); 3) demência vascular (DV). Resultados e discussão: 0 desempenho em testes neuropsicológicos diferiu entre os grupos, sendo o desempenho tanto pior quanto maior o comprometimento. O grupo DV provável demonstrou desempenho prejudicado na memória, velocidade de processamento e produção verbal, enquanto o grupo CCVSD apresentou déficit de atenção. Conclusão: Prejuízos nas funções executivas e dificuldades em AVDs permitem diferenciar os níveis de comprometimento nos grupos de doença vascular subcortical.

Palavras-Chave: comprometimento cognitivo, demência vascular, avaliação neuropsicológica, atividades cotidianas.

Vascular cognitive impairment (VCI) has superseded vascular dementia and multi-infarct dementia as the concept to be used in cognitive decline secondary to cerebrovascular disease ${ }^{1}$.

The prevalence of dementia increases with age, and the prevalence of vascular dementia in epidemiological studies varies between 22 and 26.28\% $\%^{2,3}$. An epidemiologic study in Brazil showed a prevalence of $9.3 \%$ for vascular dementia (VaD) among demented participants aged 64 years and older 4 . Studies in tertiary outpatient clinics report a prevalence of vascular dementia between 24.9 and $32.25 \%$,5, and of $36.9 \%$ in a sample with presenile dementia?
VCI is a risk factor for the development of dementia. Wentzel ${ }^{8}$ observed that half of the subjects with vascular cognitive impairment with no dementia (VCIND) developed dementia over a five-year period. The current findings suggest that poor mental flexibility and verbal retrieval in the context of preserved function in other domains may characterize the prodromal stage of $\mathrm{VaD}^{9}$. Cognitive impairment with vascular disease often occurs in domains of selective or divided attention, executive function (frontal lobe function) and processing speed ${ }^{10}$.

Chui ${ }^{11}$ compared groups with dementia secondary to vascular disease presenting ischemic subcortical lesions (VADIS)

${ }_{1}^{1}$ Psychologist, Federal University of São Paulo (UNIFESP), São Paulo SP, Brazil;

${ }^{2}$ MD, PhD, UNIFESP, São Paulo SP, Brazil, Santa Marcelina Hospital, São Paulo SP, Brazil;

${ }^{3}$ Psychologist, UNIFESP, São Paulo SP, Brazil;

${ }^{4} \mathrm{MD}$, Federal University of Ceará (UFC), Fortaleza CE, Brazil.

Correspondence: Sonia Maria Dozzi Brucki; Rio Grande 180/61; 04018-000 São Paulo SP - Brasil; E-mail: sbrucki@uol.com.br

Support: This work was supported by a grant provided by the Fundação de Amparo à Pesquisa do Estado de São Paulo - FAPESP (04/11436-5) and Associação Fundo de Incentivo à Psicofarmacologia - AFIP.

Conflict of interest: There is no conflict of interest to declare.

Received 03 November 2010; Received in final form 21 November 2011; Accepted 28 November 2011 
against those with Alzheimer disease $(\mathrm{AD})$, and verified that the pattern of cognitive damage in VADIS is characterized by more extensive compromise of executive function, although with greater preservation in recognition memory.

Several studies in the literature have sought to describe a model of cognitive profile for $\mathrm{VaD}$, but, due to the varied forms of clinical manifestations, dependent on the types and locations of the vascular lesions, no single model exists for the entity $^{12}$. Rockwood et al. ${ }^{13}$ suggest that the cognitive syndrome of vascular disease is characterized by the predominance of executive dysfunction in contrast with the deficits of memory and language typical of patients with $\mathrm{AD}$. Subcortical VaD presents a more homogeneous cognitive profile characterized by executive dysfunction and less severe impairment of memory ${ }^{12-15}$.

The aims of this study were to evaluate the cognitive functions in patients with subcortical vascular lesions, focusing on executive functions, and observe the functional losses with impairment in ADLs of each patient group in order to detect primary symptoms thereby enabling dementia prevention.

\section{METHODS}

\section{Participants}

A total of 50 patients with vascular subcortical lesions (including white periventricular matter, thalamus and basal ganglia lesions) were selected from medical files of an outpatient memory clinic of the Santa Marcelina Hospital and matched (according to age, gender and education) with 50 healthy elderly controls. The patients who had subcortical lesions according to medical records were invited to participate in the study and classified by an experienced neurologist. All patients were at a chronic phase more than three months after confirmed stroke. Medical history, neurological examination and MRI were performed in all subjects. Patients were classified into three groups according to scores obtained on the Mini-Mental State Examination (MMSE), based on the education level for the adapted Brazilian scale ${ }^{16}$, and on the Functional Activity Questionnaire (FAQ) ${ }^{17}$ (Table 1). This classification was later confirmed by the results of neuropsychological tests: no vascular cognitive impairment (NVCI): $\mathrm{FAQ}<4$ and MMSE scores $\geq$

Table 1. Classification into three groups according to scores obtained on the Mini-Mental State Examination (MMSE), based on the education level for the adapted Brazilian scale.

\begin{tabular}{|c|c|c|c|c|c|}
\hline \multicolumn{2}{|c|}{$\mathrm{NVCl}$} & \multicolumn{2}{|c|}{ VCIND } & \multicolumn{2}{|c|}{$\mathrm{VaD}$} \\
\hline \multicolumn{2}{|c|}{$F A Q<4$} & \multicolumn{2}{|c|}{$F A Q<4$} & \multicolumn{2}{|c|}{$F A Q>4$} \\
\hline Education & MMSE & Education & MMSE & Education & MMSE \\
\hline Illiterates & $\geq 20$ & Illiterates & $18-20$ & Illiterates & $<18$ \\
\hline $1-4$ & $\geq 25$ & $1-4$ & $23-25$ & $1-4$ & $<23$ \\
\hline $5-8$ & $\geq 26$ & $5-8$ & $24-26$ & $5-8$ & $<24$ \\
\hline $9-11$ & $\geq 28$ & $9-11$ & $26-28$ & $9-11$ & $<26$ \\
\hline$\geq 12$ & $\geq 29$ & $\geq 12$ & $\geq 29$ & $\geq 12$ & $<26$ \\
\hline
\end{tabular}

NVCl: no vascular cognitive impairment; VCIND: vascular cognitive impairment with no dementia; VaD: vascular dementia; FAQ: functional activity questionnaire. median value for education; VCIND: FAQ $<4$ and MMSE score between - 1.5 SDs and mean value for educational level; and VaD: patients with probable $\mathrm{VaD}$ according to NINDS-AIREN criteria $^{16}, \mathrm{FAQ}>4$ and MMSE $<1.5 \mathrm{SD}$ s from the mean.

The exclusion criteria for the patients were: aphasia; severe paresis in dominant hand; uncorrected visual or hearing deficit; use of medications that directly affect the central nervous system, such as benzodiazepines, anticholinergics drugs and neuroleptics; orthopedic or rheumatologic disturbances that could affect the exam; presence of areas of cortical ischemia on magnetic resonance imaging.

\section{Control group}

Healthy control subjects were matched by age and educational level to each group of vascular patients. Controls were selected based on FAQ scores of less than 4 points and MMSE scores above the mean for each educational level. The control group included individuals drawn from the community, spouses and patients of the other specialties who fulfilled the inclusion criteria. Controls had no psychiatric or neurological diseases; no use of drugs with central nervous system action; no risk factors for cerebrovascular disease; no uncorrected sensory impairment; and no motor compromise due to orthopedic or rheumatologic conditions. Controls were matched with each patient group.

After assessment of the functional activities using the FAQ and brief cognitive evaluation through the MMSE, patients and controls were submitted to a neuropsychological examination with a psychologist blinded to their condition.

The demographic data (gender, age and education) of the study are shown in Table 2, with baseline MMSE and FAQ scores. We found no significant differences among the variables age, education and gender.

The study was approved by the Ethics Committees of the Federal University of São Paulo and of Santa Marcelina Hospital. All subjects gave prior written consent for participation in the study.

\section{Neuropsychological assessment}

Neuropsychological assessment included digit $\operatorname{span}^{18}$ : attention span, mental control and capacity to retain and manipulate verbal information; logical memory ${ }^{18}$ : episodic memory in immediate and delayed recall; Wisconsin Card Sorting Test (WCST) $)^{18}$ : the capacity to form concepts and mental flexibility; Trail Making Test (TMT) A and $\mathrm{B}^{18}$ : speed of visuospatial search, attention and mental flexibility; Rey Complex Figure - copy and delayed recall ${ }^{18}$ : planning, nonverbal memory, visual and space perception and praxis.

It was applied the Clock Test - CLOX ${ }^{19}$, in which subjects are asked to "draw a clock showing 1.45 " on the back of a score sheet, through which a black circle is displayed in the bottom righthand corner (CLOX 1). Once completed, the examiner draws the clock as required in front of the subject, placing 12, 6, 3 and 9 first, then setting the hands to ' 1.45 ' and making them into arrows. The subject then has to copy the examiner's clock (CLOX 2). 
Moreover, in the assessment were include Stroop Test ${ }^{18}$ : inhibition of a habitual answer rather than an unusual answer, and to mental flexibility, impulsiveness and inhibitory control; verbal fluency: tests were accomplished by phonemic category - $\mathrm{FAS}^{18}$ is requested to utter as many words as possible starting with the letter 'F', 'A' and 'S'; semantic category - animals ${ }^{18}$, it is expected that the patient state, within $60 \mathrm{sec}$ onds, as many names of animals as possible; test of excluding letters ${ }^{20}$ : assesses executive function while requiring control of impulsive answers. It consists of the generation of words for one minute, excluding a letter (in this case, letter E).

\section{Functional evaluation of the activities of daily living}

Participants were evaluated according to the FAQ scores.

\section{STATISTICAL ANALYSIS}

The Statistical Package for the Social Sciences (SPSS) - version 13.0 was used for data analysis. Non-parametric tests were used to evaluate non-categorical variables among groups. The MannWhitney test verified possible differences among VaD, VCIND and NVCI groups and their respective controls. The KruskalWallis Test was applied to compare VaD, VCIND and NVCI groups for performance on neuropsychological tests. Differences among the groups were analyzed using the Mann-Whitney Test, and Spearman's Correlation was performed to verify the relationship between ADLs and the neuropsychological tests. The level of significance was set at 0.05. A forward stepwise logistic regression analysis (diagnosis of yes/no cognitive impairment as dependent variable) was performed to establish the independent predictive ability of tests that presented p values less than 0.05 after the Mann-Whitney test. In order to perform the logistic regression analysis, we used the Mann-Whitney test to compare groups (yes or no cognitive impairment), to determine which tests could be elected for the regression model. To this, it was considered that a variable could be eligible if $p<0.200$. We applied the logistic regression analysis in function on the dependent variable 'group'. Once we found the variables (neuropsychological tests) eligible to the modeling process through the application of logistic regression analysis, we constructed a regression model with four variables, which achieved the balance of the regression model.

\section{RESULTS}

Table 3 shows the mean and standard deviations on those tests revealing a significant difference among patient groups, with differences between each group. We found poorer performance associated with severity of clinical

Table 2. Demographic data of study and control groups.

\begin{tabular}{|c|c|c|c|c|c|c|}
\hline \multirow{3}{*}{ Variable } & & \multicolumn{4}{|c|}{ Groups } & \multirow{3}{*}{$p$-value } \\
\hline & & Controls & $\mathrm{NVCl}$ & VCIND & $\mathrm{VaD}$ & \\
\hline & & $n=50$ & $n=12$ & $n=10$ & $n=28$ & \\
\hline Sex & & $F=25 \quad M=25$ & $F=9 \quad M=3$ & $F=4 M=6$ & $F=12 M=16$ & $0.265^{1}$ \\
\hline Age & Mean (SD) & $66.1(9.1)$ & $65.3(10.3)$ & $62.3(9.2)$ & $67.8(8.1)$ & $0.378^{2}$ \\
\hline Education & Mean (SD) & $5.9(4.5)$ & $7.8(4.1)$ & $4.9(3.9)$ & $5.3(5.0)$ & $0.193^{2}$ \\
\hline MMSE & Mean (SD) & $28.5(2.1)$ & $27.6(1.7)$ & $24.1(4.1)$ & $20.8(4.5)$ & $<0.001^{2}$ \\
\hline
\end{tabular}

${ }^{1}$ Chi-Square; ${ }^{2}$ Kruskal-Wallis Test; MMSE: Mini-Mental State Examination; NVCl: no vascular cognitive impairment; VCIND: vascular cognitive impairment with dementia; VaD: vascular dementia.

Table 3. Scores on neuropsychological tests and statistical differences among patient groups.

\begin{tabular}{|c|c|c|c|c|c|c|c|}
\hline \multirow{4}{*}{ Variable } & \multicolumn{6}{|c|}{ Groups } & \multirow{4}{*}{$p$-value* } \\
\hline & \multirow{2}{*}{\multicolumn{2}{|c|}{$\begin{array}{l}\mathrm{NVCl} \\
\mathrm{n}=10\end{array}$}} & \multirow{2}{*}{\multicolumn{2}{|c|}{$\begin{array}{c}\text { VCIND } \\
n=12\end{array}$}} & \multirow{2}{*}{\multicolumn{2}{|c|}{$\begin{array}{c}\mathrm{VaD} \\
\mathrm{n}=28\end{array}$}} & \\
\hline & & & & & & & \\
\hline & Mean & SD & Mean & SD & Mean & SD & \\
\hline Rey_copy & $27.1^{a . c}$ & 6.1 & $17.8^{a}$ & 9.2 & 14.3 & 12.9 & 0.011 \\
\hline Rey_imed & $8.6^{\circ}$ & 5.3 & 5.4 & 5.1 & 3.5 & 4.9 & 0.008 \\
\hline Rey_delayed & $8.7^{\circ}$ & 5.5 & 4.4 & 4.5 & 2.4 & 3.9 & 0.003 \\
\hline Log_mem1 & $14.67^{\circ}$ & 4.6 & $11.7^{b}$ & 5.5 & $7.9^{b}$ & 6.8 & 0.003 \\
\hline Log_mem2 & $9.6^{a . c}$ & 5.4 & $5.0^{a}$ & 4.5 & 3.1 & 5.3 & 0.002 \\
\hline FAS & $21.3^{c}$ & 11.6 & 13.4 & 5.8 & 12.0 & 9.3 & 0.034 \\
\hline CLOX2 & $12.8^{\mathrm{c}}$ & 1.6 & $12.4^{b}$ & 1.9 & $8.6^{b}$ & 4.9 & 0.009 \\
\hline Animals & $11.0^{\circ}$ & 2.5 & 10.1 & 4.7 & 7.6 & 3.2 & 0.015 \\
\hline Let_Exclud & $10.4^{\mathrm{a} . \mathrm{c}}$ & 4.1 & $6.0^{\mathrm{a}}$ & 4.5 & 5.5 & 4.2 & 0.005 \\
\hline Stroop1_Time & $25.9^{\circ}$ & 9.4 & 31.9 & 11.9 & 53.5 & 29.7 & 0.002 \\
\hline MMSE & $27.6^{a . c}$ & 1.7 & $24.1^{a}$ & 4.1 & 20.8 & 4.5 & $<0.001$ \\
\hline$F A Q$ & $1.2^{\mathrm{c}}$ & 1.4 & $3.2^{b}$ & 3.2 & $16.9^{b}$ & 8.3 & $<0.001$ \\
\hline
\end{tabular}

*Kruskal-Wallis Test; NVCl:no vascular cognitive impairment;VCIND:vascular cognitive impairment with no dementia;VaD:vascular dementia; MMSE: mini-mental state

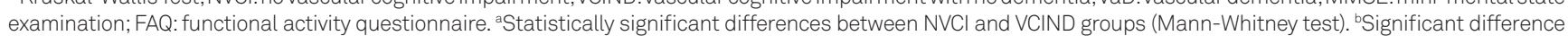
between VCIND and probable VaD groups (Mann-Whitney test). ${ }^{\circ}$ Significant difference between NVCl and probable VaD groups (Mann-Whitney test). ${ }^{\mathrm{a}, \mathrm{b}, \mathrm{c}} \mathrm{p}<0.05$. 
condition. There was no difference among groups on the following tests: trail making test, WCST, Stroop Test, forward and backward digit span.

Table 4 depicts results of each group and their controls, matched by age and educational level, on neuropsychological tests. We observed significant statistical differences among VaD patients and their respective controls on verbal and nonverbal memory tests (immediate and delayed recall), on visuospatial perception and construction tasks, on verbal fluency tests, speed processing, categorization, abstract thinking, attention and working memory.

Comparison among VCIND patients and their controls revealed statistical differences on tests measuring visuoperception and construction, verbal fluency, sustained attention, processing speed, categorization and abstraction.

Comparisons between NVCI and the control group showed differences on tests of phonemic verbal fluency, visual construction, sustained attention, speed of processing, categorization and abstract thinking.

As expected, a negative correlation between FAQ scores $(\mathrm{r}=-0.387, \mathrm{p}<0.001)$ was found. Correlations were performed to determine whether these measures (FAQ) were associated with neuropsychological functions (Table 5).
Based on results of the Mann-Whitney test, Animals, WCST_categ and Span_OI were selected for input to the logistic regression model. In general and concomitantly, the lower the value of Animals, of WSCT_Categ and of Span_OI and the larger the value on the FAQ, then the higher the probability of having the cognitive impairment when FAQ yields medium to high values, independently of the other variables. (Table 6).

These results showed that neuropsychological profiles differ among vascular severity groups.

\section{DISCUSSION}

Vascular cognitive impairment can be defined as cognitive alterations due to cerebrovascular lesions, in which cognition is impaired at various degrees of severity ${ }^{21}$. We have classified patients with subcortical ischemic lesions by cognitive level based on a screening test (MMSE) and a functional activities questionnaire, with vascular dementia ranging from no evidence of cognitive impairment to vascular dementia.

The MMSE cutoff scores overlapped between groups, maybe due to lack of sensitivity to subcortical cognitive

Table 4. Comparison among VaD, VCIND and NVCI groups with their respective controls.

\begin{tabular}{|c|c|c|c|c|c|c|}
\hline \multirow{2}{*}{ Variable } & $\mathrm{NVCl}$ & Controls & VCIND & Controls & $\mathrm{VaD}$ & Controls \\
\hline & Mean (SD) & Mean (SD) & Mean (SD) & Mean (SD) & Mean (SD) & Mean (SD) \\
\hline Rey_time & $536.8(394.7)$ & $377.3(168.9)$ & $415.0(164.8)^{\#}$ & $267.8(113.9)^{\#}$ & $406.0(223.9)$ & $375.8(244.1)$ \\
\hline Rey_copy & $27.1(6.1)$ & $30.3(7.4)$ & $17.8(9.2)^{\#}$ & $28.6(7.9)^{\#}$ & $14.3(12.9)^{\#}$ & $26.6(9.4)^{\#}$ \\
\hline Rey_imed & $8.6(5.3)$ & $10.5(7.0)$ & $5.4(5.1)$ & $10.0(7.1)$ & $3.5(4.9)^{\#}$ & $9.8(6.8)^{\#}$ \\
\hline Rey_delayed & $8.7(5.5)$ & $10.0(7.3)$ & $4.4(4.5)$ & $8.5(5.0)$ & $2.4(3.9)^{\#}$ & $9.5(6.9)^{\#}$ \\
\hline Log_Mem1 & $14.7(4.6)$ & $14.4(6.1)$ & $11.7(5.5)$ & $12.6(5.0)$ & $7.9(6.8)^{\#}$ & $13.5(6.2)^{\#}$ \\
\hline Log_Mem2 & $9.6(5.4)$ & $9.9(7.2)$ & $5.0(4.5)$ & $7.4(2.4)$ & $3.1(5.3)^{\#}$ & $8.2(6.4)^{\#}$ \\
\hline FAS & $21.3(11.6)^{\#}$ & $26.3(5.7)$ & $13.4(5.9)^{\#}$ & $22.0(8.8)^{\#}$ & $12.0(9.3)^{\#}$ & $24.3(11.7)^{\#}$ \\
\hline CLOX1 & $9.4(2.6)^{\#}$ & $11.4(1.6)$ & $6.1(4.1)$ & $8.1(3.3)$ & $6.0(4.7)^{\#}$ & $9.3(4.1)^{\#}$ \\
\hline CLOX2 & $12.8(1.6)$ & $13.1(1.9)$ & $12.4(1.9)$ & $13.1(1.3)$ & $8.6(4.9)^{\#}$ & $12.6(1.9)^{\#}$ \\
\hline Animals & $11.0(2.5)$ & $13.4(3.0)$ & $10.1(4.7)^{\#}$ & $14.5(4.2)^{\#}$ & $7.6(3.2)^{\#}$ & $13.0(4.1)^{\#}$ \\
\hline TMT-A_Time & $110.2(59.9)^{\#}$ & $70.3(38.4)$ & $168.2(132.0)^{\#}$ & $62.4(36.0)^{\#}$ & $257.9(196.9)^{\#}$ & $112.0(82.0)^{\#}$ \\
\hline TMT-A_Errors & $0.2(0.4)$ & $0.1(0.3)$ & $0.4(0.7)$ & $0.0(0.0)$ & $0.7(1.1)$ & $0.5(1.1)$ \\
\hline TMT-B Time & $311.9(175.7)^{\#}$ & $167.6(94.0)$ & $373.3(162.5)^{\#}$ & $158.1(87.3)^{\#}$ & $377.8(220.0)$ & $244.7(168.4)$ \\
\hline TMT-B_Errors & $1.5(1.2)^{\#}$ & $0.3(1.0)$ & $0.8(1.5)$ & $0.4(0.7)$ & $1.5(1.5)$ & $0.9(1.2)$ \\
\hline Exclud_Letter & $10.4(4.1)$ & $13.4(2.7)$ & $6.0(4.5)^{\#}$ & $15.2(4.5)^{\#}$ & $5.5(4.2)^{\#}$ & $11.5(4.5)^{\#}$ \\
\hline Stroop1_Time & $25.9(9.4)^{\#}$ & $18.4(4.8)$ & $31.9(11.9)^{\#}$ & $19.1(4.1)^{\#}$ & $53.5(29.7)^{\#}$ & $23.9(10.2)^{\#}$ \\
\hline Stroop1_Errors & $0.5(0.9)$ & $0.0(0.0)$ & $0.2(0.7)$ & $0.0(0.0)$ & $1.1(1.4)^{\#}$ & $0.1(0.4)^{\#}$ \\
\hline Stroop2_Time & $35.8(10.5)^{\#}$ & $26.3(10.9)$ & $47.3(18.2)^{\#}$ & $26.5(8.7)^{\#}$ & $76.5(73.0)^{\#}$ & $32.3(13.9)^{\#}$ \\
\hline Stroop2_Errors & $0.3(0.7)$ & $0.0(0.0)$ & $0.6(1.2)$ & $0.0(0.0)$ & $1.3(2.0)^{\#}$ & $0.1(0.3)^{\#}$ \\
\hline Stroop3_Time & $50.8(15.7)$ & $46.4(18.6)$ & $66.6(24.9)^{\#}$ & $41.2(8.3)^{\#}$ & 104.5 (96.1)\# & $50.5(21.5)^{\#}$ \\
\hline Stroop3_Errors & $2.1(1.6)$ & $1.9(1.6)$ & $2.6(2.1)$ & $2.1(2.2)$ & $5.2(4.9)$ & $2.5(2.5)$ \\
\hline WCST_Categ & $1.4(0.9)^{\#}$ & $3.2(1.4)$ & $1.0(1.4)^{\#}$ & $2.6(1.2)^{\#}$ & $1.1(1.2)^{\#}$ & $2.3(1.0)^{\#}$ \\
\hline WCST_ErPers & $28.6(16.0)$ & $13.5(8.2)$ & $46.0(1.4)$ & $8.6(4.7)$ & $24.2(15.0)$ & $19.3(10.7)$ \\
\hline WCST_PerdaSet & $0.6(1.0)$ & $0.6(0.5)$ & $1.3(1.2)$ & $0.6(0.5)$ & $0.4(0.9)$ & $0.5(0.6)$ \\
\hline Span_forward & $4.9(2.4)$ & $6.5(1.5)$ & $3.6(1.1)$ & $5.0(2.4)$ & $4.2(1.6)^{\#}$ & $5.3(2.1)^{\#}$ \\
\hline Span_backward & $3.6(1.8)$ & $3.3(1.7)$ & $2.6(1.4)$ & $4.0(1.9)$ & $2.9(1.3)^{\#}$ & $3.8(1.5)^{\#}$ \\
\hline
\end{tabular}

*Mann-Whitney test; ( $<<0.05)$; VaD: vascular dementia; VCIND: vascular cognitive impairment with no dementia; NVCl: no vascular cognitive impairment; TMT: trail making test; WCST: wisconsin card sorting test. \#significant difference between control and patient group. 
impairment or owing to the inability to distinguish slight differences among VCI profiles, but largely due to an expected overlap of cutoff scores. Notwithstanding, the groups presented clear differences on many cognitive measures, showing a clear-cut division.

Our results showed progressive impairment in many executive functions from the NVCI to the probable VaD group, in phonemic fluency, visuospatial skills and sustained attention, strategy and constructional praxis, divided attention, categorization and abstract thinking tests, as well as in verbal and nonverbal memory tests. It is important to emphasize that TMT-B was greatly compromised in the Probable VaD group, with many patients unable to complete the task, proving to be a difficult type of test for low educated subjects.

Significant differences were found between the studied groups and their controls, with the probable VaD group being most impaired in relation to their controls. As observed, the NVCI group had poorer performance than their controls on many cognitive measures, particularly in relation to verbal

Table 5. Correlation among scores on FAQ and neuropsychological tests.

\begin{tabular}{lcc} 
& \multicolumn{2}{c}{ Correlation coefficient/p value } \\
\cline { 2 - 3 } Neuropsychological tests & \multicolumn{2}{c}{ FAQ } \\
\cline { 2 - 3 } & -0.443 & -value \\
\hline Rey_copy & -0.414 & $<0.001$ \\
Rey_imed & -0.488 & $<0.001$ \\
Rey_delayed & -0.430 & $<0.001$ \\
Log_Mem1 & -0.522 & $<0.001$ \\
Log_Mem2 & -0.563 & $<0.001$ \\
FAS & -0.353 & $<0.001$ \\
CLOX1 & -0.418 & $<0.001$ \\
CLOX2 & -0.549 & $<0.001$ \\
Animals & 0.462 & $<0.001$ \\
TrailA_Time & 0.413 & 0.001 \\
TrailB_Time & -0.576 & $<0.001$ \\
Let_Exclud & 0.616 & $<0.001$ \\
Stroop1_Time & 0.518 & $<0.001$ \\
Stroop1_Errors & 0.492 & $<0.001$ \\
Stroop2_Time & 0.539 & $<0.001$ \\
Stroop2_Errors & 0.440 & $<0.001$ \\
Stroop3_Time & 0.336 & 0.003 \\
Stroop3_Errors & -0.500 & $<0.001$ \\
WCST_Categ & -0.246 & 0.015 \\
Span_forward & -0.245 & 0.015 \\
Span_backward & &
\end{tabular}

*Spearman's correlation; FAQ: functional activity questionnaire; WCST: wisconsin card sorting test. fluency, visuospatial skills and sustained attention, and on strategy and constructional praxis, divided attention, categorization and abstract thinking. This indicates that early evaluation of these functions could prevent more serious conditions, as patients were functionally adequate. According to Laukka ${ }^{22}$, cognitive deficits could be presented in a preclinical phase of $\mathrm{VaD}$, resulting from circulatory disturbances that could affect cerebral function before dementia is diagnosed. In our study, we found poorer results in patients with no cognitive impairment on the screening test and with preserved ADLs (NVCI group), perhaps suggesting that these tests are effective at screening for very mild cognitive impairments in patients with ischemic subcortical lesions.

All patient groups performed worse than their controls on tests of verbal fluency, processing speed and abstract thinking akin to other reports ${ }^{19}$ which compared healthy controls to VCI and VaD patients.

The VCIND group had impaired performance in relation to their controls on tests related to cortico-subcortical pathways, although demonstrated intact functional ADL. These patients presented depressive symptoms that did not correlate with neuropsychological performance. This fact allows us to make some inferences in VCIND profile subjects, for example, that there is early compromise of executive functions which cannot be explained by depressive symptoms alone. Pantoni and colleagues ${ }^{12}$ showed that the VCIND group demonstrated significant difficulties on measures of cognitive flexibility, verbal retrieval and verbal recognition memory, but not on measures of confrontational naming or verbal fluency. The probable VaD group was impaired on all cognitive measures assessed, suggesting that poor cognitive flexibility and verbal retrieval in the context of preserved function in other domains may characterize the prodromal stage of $\mathrm{VaD}$.

Our findings comparing VCIND and probable VaD groups were similar to those of the study by Stephens et al. ${ }^{23}$ who described compromise of executive functions in both these patient groups ascribing this to early damage in VCI. Other studies have reported similar findings, in addition to decline in ADLs and frequent depressive symptoms ${ }^{24,25}$.

However, we noted that in mild stages of impairment, such as in VCIND, there is significant compromise of visual construction, verbal fluency, visuospatial skills, attention, abstraction thinking, inhibitory control and processing speed.

The VCIND group presented impairment in mental flexibility whereby this group committed the largest number of

Table 6. Logistic regression.

\begin{tabular}{|c|c|c|c|c|c|c|c|}
\hline \multirow{2}{*}{ Variable } & \multirow{2}{*}{ Coefficient } & \multirow{2}{*}{ S.E. } & \multirow{2}{*}{ Z } & \multirow{2}{*}{ Odds Ratio } & \multicolumn{2}{|c|}{$95 \% \mathrm{Cl}$} & \multirow{2}{*}{$p$-value } \\
\hline & & & & & Lower & Upper & \\
\hline Animais & -0.421 & 0.274 & 2.361 & 0.656 & 0.383 & 1.123 & 0.124 \\
\hline WCST_categ & -2.071 & 1.087 & 3.634 & 0.126 & 0.015 & 1.060 & 0.057 \\
\hline Span_Ol & 1.556 & 0.820 & 3.601 & 4.740 & 0950 & 23.650 & 0.058 \\
\hline
\end{tabular}

WCST: wisconsin card sorting test; SE: standard error. 
perseverative errors on the WCST. This finding is in agreement with the study of Garret et al. ${ }^{9}$ who observed significant difficulties in mental flexibility in their sample of VCIND patients.

In the study by Stephens et al. ${ }^{23}$, deficits in attention and executive function were observed in patients with stroke, but without cognitive impairment (NVCI), compared to controls. Comparing these patients with a group of patients with vascular cognitive impairment without dementia, they observed that the latter had greater impairment in tests of executive functions, memory and language. Our comparison between NVCI and VCIND groups yielded the same results as the study by Stephens, since our VCIND group was significantly more impaired on tests of memory and language. In our study, we also detected significant differences between the NVCI group and controls on the tests evaluating attention and executive functions (TMT-B, Stroop and WCST).

Comparison of our VCIND and probable VaD groups yielded results similar to those found by Stephens. Our patients differed in episodic memory, visuoconstructive ability and ADLs.

We observed a pattern of decreased cognitive functions according to the degree of early impairment in executive functions and verbal fluency, and deficits in visual-spatial skills, divided attention and abstract thinking in individuals with vascular lesions. These deficits were greater in subjects with VCIND than in ones with NVCI, and we also observed compromise in planning and mental control, even in individuals with $\mathrm{VaD}$ in that all the tests of executive functions were impaired, indicating early impairment of dopaminergic and cholinergic pathways that traverse the subcortical white matter ${ }^{26}$.

Depressive symptoms are common in patients with cerebrovascular disease, and cognitive impairment is common in geriatric depression. Also, depressed individuals with comorbid cognitive impairment are at increased risk for a number of adverse medical, psychiatric and cognitive outcomes ${ }^{27}$. Therefore, it is always important to differentiate executive dysfunction and depressive symptoms for adequate therapeutic conduct.

We also noted significant correlation between FAQ scores and neuropsychological measures. The results of our study reveal that patients with subcortical vascular lesions have cognitive impairment, mainly in executive functions, difficulties in ADLs and presence of depressive symptoms, indicating that searching for these types of signs and symptoms proves to be effective for early diagnosis of VCI.

Some patients presented very mild cognitive impairment, that did not result in significant ADL difficulties, and few depressive symptoms. Such cases in our survey were denoted as NVCI. In these subjects, only a neuropsychological evaluation verified decreased performance. These findings could point to a need for a more detailed evaluation in patients with subcortical lesions for early diagnosis. In these cases, it is possible that neuropsychological evaluation could represent a gold standard method for diagnosis at basal measurement in order to follow cognitive outcome.

Some limitations should be observed in our study. These concern the severity of subcortical ischemic lesions, since no ranking scale was used to evaluate their presence at the time of evaluation, precluding correlation of lesion severity with cognitive impairments. Unfortunately, we did not use quantitative scales of white matter hyperintensities or quantification of brain volume loss. Nevertheless, our patients were carefully selected with respect to the presence of subcortical lesions, seen on magnetic resonance imaging. All patients had been at a chronic phase for more than three months after confirmed stroke. The sample size was relatively small in the VCI and NVCI groups, but patients were highly selected. We believe that limitations regarding the number of patients were minimized by matching each type of patient group with its own control group, providing a neuropsychological profile with considerable consistency. Possible education influence on majority of the tests was minimized homogenizing the samples by matching for schooling.

Our results allow us to conclude that there is a continuum in cognitive profiles, from mild signs of cognitive impairment to incontestable dementia, despite the fact this was a transversal study. The pattern of cognitive deficit of VCIND and $\mathrm{VaD}$ are similar, except that in the probable $\mathrm{VaD}$ group the deficits tend to be greater than in the VCIND group. All patient groups presented difficulties on tests evaluating executive functions (planning, mental control, abstraction, perseveration, inhibitory control and processing speed), albeit to different degrees.

The results showed that executive impairments manifest early in mild impairment among subcortical ischemic lesion patients, who also present an increased frequency of depressive symptoms, as well as some difficulties in ADLs. Evaluation of functional activity seems to be a valuable approach for early detection of vascular cognitive impairment.

\section{References}

1. BowlerJV.Modern concept of vascular cognitive dementia impairment. Br Med Bull 2007;83:291-305.

2. Vas CJ, Pinto C, Panikker D, et al. Prevalence of dementia in an urban Indian population. Int Psychogeriatr 2001;13:439-450.

3. Rocca WA, Hofman A, Brayne C, et al. The prevalence of vascular dementia in Europe: facts and fragments from 1980-1990 studies. EURODEM-Prevalence Research Group. Ann Neurol 1991;30:817-824.

4. Herrera Jr. E, Caramelli P, Nitrini R. Population epidemiologic study of dementia in Catanduva city: state of Sao Paulo, Brazil. Rev Psiquiatr Clín 1998; 25:70-73. 
5. Silva DW, Damasceno BP. Demência na população de pacientes do Hospital das Clínicas da UNICAMP. Arq Neuropsiquiatr 2002; 60:996-999

6. Vale FA, MirandaSJ.Clinical and demographic features of patients with dementia attended in a tertiary outpatient clinic. Arq Neuropsiquiatr 2002;60:548-552.

7. Fujihara S. Brucki SMD, Rocha MSG, Carvalho AA, Piccolo AC. Prevalence of presenile dementia in a tertiary outpatient clinic. Arq Neuropsiquiatr 2004;62:592-595.

8. Wentzel C, Rockwood K, Macknight C, et al. Progression of impairment in patients with vascular cognitive impairment without dementia. Neurology 2001;57:714-716.

9. Garret KD, Browndyke JN, Whelihan W, et al. The neuropsychological profile of vascular cognitive impairment-no dementia: comparisons to patients at risk for cerebrovascular disease and vascular dementia. Arch Clin Neuropsychol 2004;19:745-757.

10. Jager CA, Hogervorst E, Combrinck M, Budge MM. Sensitivity and specificity of neuropsychological tests for mild cognitive impairment, vascular cognitive impairment and Alzheimer's disease. Psychol Med 2003;33:1039-1050

11. Chui H. Dementia due to subcortical ischemic vascular disease. Clin Cornerstone 2001;3:40-51.

12. Pantoni L, Leys D, Fazekas F, et al. Role of the white matter lesions in cognitive impairment of vascular origin. Alzheimer Dis Assoc Disord 1999;13(Suppl 3):S49-S54.

13. Rockwood K, Bowler J, Erkinjuntti T, Hachinski V, Wallin A. Subtypes of vascular dementia. Alzheimer Dis Assoc Disord 1999;13(Suppl 3): S59-S65.

14. Pohjasvaara T, Mäntylä R, Ylikoski R, Kaste M, ErkinjunttiT.Comparison of different clinical criteria (DSM-III, ADDTC, ICD-10, NINDS-AIREN, DSM-IV) for the diagnosis of vascular dementia. National Institute of Neurological Disorders and Stroke-Association Internationale pour la Recherche et l'Enseignement en Neurosciences. Stroke 2000;31:2952-2957.
15. Román GC. Defining dementia: clinical criteria for the diagnosis of vascular dementia. Acta Neurol Scand Suppl 2002;17806(Suppl 178): S6-S9.

16. Brucki SMD, Nitrini R, Caramelli P, Bertolucci PHF, Okamoto $I H$ Sugestões para o uso do Mini-Exame do Estado Mental no Brasil. Ara Neuropsiquiatr 2003;61:771-781.

17. Pfeffer RI, Kurosaki TT, Harrah CH, Chance JM, Filos S. Measurement of functional activities in older adults in the community. J Gerontol 1982;37:323-329.

18. Spreen O, Strauss E. A Compendium of Neuropsychological Tests. New York. Oxford University Press; 1991.

19. Royall DR, Cordes J, Polk M. CLOX: an executive clock drawing task. J Neurol Neurosurg Psychiatry 1998;64:588-594.

20. Bryan J, Luszcz MA, Crawford JR. Verbal knowledge and speed of information processing as mediators of age differences in verbal fluency performance among older adults. Psychol Aging1997;12:473-478.

21. Yesavage JA, Brink TL, Rose TL, et al. Development and validation of a geriatric depression screening scale: a preliminary report.J Psychiatr Res 1982-1983;17:37-49.

22. Laukka EJ, Jones S, Fratiglioni L, Bäckman L. Cognitive functioning in preclinical vascular dementia a 6-year follow-up. Stroke 2004;35:1805-1809.

23. Stephens S, Kenny RA, Rowan E, et al. Neuropsychological characteristics of mild vascular cognitive impairment and dementia after stroke. Int J Geriatr Psychiatry 2004;19:1053-1057.

24. Bartrés-Faz D, Clemente IC, Junqué C. White matter changes and cognitive performance in aging. Rev Neurol 2001;33:347-353.

25. Steffens DC, Potter GG. Geriatric depression and cognitive impairment. Psychol Med 2008;38:163-175.

26. Engelhardt E, Moreira DM, Laks J. Vascular dementia and the cholinergic pathways. Dement Neuropsychol 2007;1:2-9.

27. Starkstein S, Robinson RG. Affective disorders and cerebral vascular disease. Br J Psychiatry 1989;154:170-182. 